\title{
A Causal Analysis of the Sense of Community for High-rise Residents in Bangkok Metropolitan Area
}

\author{
Siriwan Rujibhong ${ }^{1} \&$ Prapatpong Upala $^{1}$ \\ ${ }^{1}$ Faculty of Architecture, King Mongkut's Institute of Technology Ladkrabang (KMITL), Bangkok, Thailand \\ Correspondence: Siriwan Rujibhong, Multidisciplinary Design Research, Faculty of Architecture, King \\ Mongkut's Institute of Technology Ladkrabang, Bangkok, Thailand. Tel: 66-2329-8365. E-mail: \\ siriwan.t@bu.ac.th
}

\author{
Received: August 5, $2017 \quad$ Accepted: August 21, $2017 \quad$ Online Published: September 28, 2017 \\ doi:10.5539/ass.v13n10p137 URL: https://doi.org/10.5539/ass.v13n10p137
}

\begin{abstract}
This multidisciplinary research focuses on investigating the environmental-psychological causality of the sense of community among high-rise housing's residents. The cross-sectional survey had been conducted in six different zones of Bangkok metropolitan area by employing the multi-stage sampling technique. Correspondingly, the 1,206 participants living in eighteen residential high-rises responded to the personal and environmental psychological (PEP) questionnaire, whereas, the physical conditions of the buildings were examined and evaluated by utilizing a non-participant observation along with the physical environmental (PE) assessment. The multiple linear regression analysis was a major approach applied for analyzing and endorsing the causal effects of the independent variables on the sense of community of the respondents, which was measured in a rating-scale type. The set of independent variables were classified into five categories, namely, (a) urban and community factors, (b) architectural factors, (c) personal attributes and dwelling behavioral factors, (d) personal psychological factors, and (e) environmental-psychological factors.

The predictive model identified ten determinants that significantly dominated the variance of the sense of community at the $95 \%$ confidence interval (significance level of .05). Regarding the final regression equation, it revealed that the communal character of the building, social capital and participation, mental health condition, relationship with neighbors, and privacy satisfaction were the factors that enhanced the high-rise residents' sense of community. On the contrary, population density, the defensible character of the building, the privacy-supportive character of the building, introvert personality of the residents, and the average of safety concern were the factors that negatively influence their sense of community.
\end{abstract}

Keywords: sense of community, high-rise housing, urban and housing development, housing environmental design, environmental psychology, urban psychology

\section{Introduction}

The vertical housing has evolved and functioned as humans' habitat for thousands of years, conspicuously in the urban area of where the agglomeration of population and infrastructures are congested. For centuries, the popularity of high-rise housing has been fluctuating. Besides the idealistic urban lifestyle, the negative consequences of living in high-rise specifically one that involves the psychological impact has been argued among the Western scholars and professionals for decades. Several previous studies suggested that high-rise residents have a poorer social relationship including a weaker sense of community than those who live in other housing types as well as pointed out the unique physical feature of the residential high-rise as a primary cause. (Forrest, La Grange, \& Ngai-Ming, 2002; Gifford, 2007)

In Bangkok, the capital city of Thailand, the high-rise housing development began in the 1970s after the end of economic recession amid Indochina Wars. (Boonkajai, 1993) Since then, the demand and supply of high-rise accommodation known as "condominium" or "condo" have been gradually enlarging due to an urban sprawl and the extreme primate city character, which progressively attract people to this metropolis. The latest decennial census in 2010 revealed that the number of Bangkok population living in the residential high-rises was several hundred thousand. (Population Statistics Group, 2010) Nevertheless, the empirical research and in-depth studies involving social behaviors and sense of community of high-rise dwellers in Thailand have been out of focus and not yet been reported academically. 
Regarding the mentioned circumstances, the objective of this study is therefore to investigate the distinctive degree of the sense of community among high-rise inhabitants and the causality of this particular psychological condition in the urban context of Bangkok. The remainder of this paper is structured as follows. Section 2 discusses the theoretical concept and previous studies related to the sense of community, and the operationalization of the conceptual variables. Section 3 describes the details of the procedures, methodology, and the implementation of the research instruments. The results of the field survey and the statistical analysis are demonstrated in Section 4. Then the interpretation and explanation of the numerical findings are further discussed in Section 5. At the end of the paper, Section 6 provides the conclusions of the study, recommendations, and directions for the future work.

\section{Theoretical framework}

\subsection{Principle and Components of Sense of Community}

The term "sense of community" was defined as a perception of similarity, interdependence, and belongingness to a particular social group of which members are sharing a common faith or commitment. (McMillan \& Chavis, 1986; Sarason, 1966; Wright, 2004) In the context of high-rise housing, besides safety and privacy, sense of community is the higher hierarchy of needs that residents could acknowledge from their home environment to fulfill the meaning of home, social recognition, empowering, moreover, to diminish their alienation. (Appleyard, 1979; DeMartino \& Stacey, 1958; Maslow, 1958; Rujibhong, Upala, \& Edelenbos, 2016) Regarding the primary components of a community: 1) territorial component (geographical notion), and 2) relational component (quality of human relationship) (Gusfield, 1975), to investigate high-rise dwellers' sense of community, the high-rise residential compound was defined as a territorial demarcation, whereas, the relationship between residents was an interested relational condition.

Among the previous research in relevant to the sense of community, the theoretical concept proposed by McMillan and Chavis in 1986 was the most influential. (Wright, 2004) They developed a Sense of Community Index (SCI-1) based on a conceptual model, in which four principles of the sense of community could be comprehended as follows: (Bess, Fisher, Sonn, \& Bishop, 2002)

1) Membership is the feeling of being or not being a part of the community. This element comprises five attributes: (a) boundaries, (b) emotional safety, (c) sense of belonging and identification, (d) personal investment, and (e) common symbol system.

2) Influence is a bi-directional concept which is required to be under the following conditions: (s) more attracted to the community they are influential, (b) cohesiveness and positive relationship between members, (c) consensual validation between individuals and the group to conform and uniform, and (d) concurrently reciprocal influence between members and group.

3) Integration and Fulfillment of Needs (Reinforcement) refers to as a primary function of a community. The community becomes strong, based on the perspective is that members of the group are being rewarded for their participation, and when people meet others' needs while they meet their own.

4) Shared Emotional Connection is composed of seven sub components as follows: (a) contact hypothesis: the more contact, the closer people are, (b) quality of interaction: the more positive relationship, the greater bond is built, (c) closer to events, (d) shared valent events, (e) investment, (f) the effect of honor and humiliation on community members, and (g) spiritual bond. (Bess et al., 2002; McMillan \& Chavis, 1986; Wright, 2004)

In 2008, Chavis had revised and proposed the SCI-2 based on the same four components mentioned above yet with more question items and supportive statistical demonstration. The SCI index was reported as the most used and broadly validated measure of sense of community. (Chavis, Lee, \& Acosta, 2008; Chipuer \& Pretty, 1999)

\subsection{Potential Factors Influencing Sense of Community}

In accordance with the previous research and studies, the driving force of the sense of community can come from multiple directions and dimensions. At the urban scale, some empirical studies indicated that the population density and heterogeneity of the neighborhoods were the dominant factors that varied the degree of sense of community. (Milgram, 1970; Takooshian, 2005) Some comparative studies conducted in Thailand concluded that among the sampling group, respondents who lived in the peripheral areas of the city reported the higher perception of the sense of community than those who resided in Bangkok urban area. (Kraithaworn \& Piasue, 2013)

For the architectural and physical environmental aspects, despite proximity between dwelling units, several studies demonstrated that the architectural features of high-rise could impersonalize the residents and 
contaminate their pro-social behaviors. (Bochner et al., 1976; Gifford, 2007; Jephcott \& Robinson, 1971) Another particular feature of the residential high-rise, which was considered as a factor impacting the sense of community of dwellers, was an access control. The previous housing research indicated that gated community had become acquiesced as an efficient access controlling approach among high-rise estates because it can secure the residents from intruders and unify the spatial identity of the residential compound. Some studies conducting in Asian metropolises concluded that it was advantageous for generating the sense of community among the residents. However, apparently, there were also arguments indicating that walls, gates, and guards, which were typical features of the gated communities, could create the "visual landscape" leading to the preconception of fear and discrimination among the dwellers (Atkinson \& Blandy, 2005; Li, 2013; Low, 2001).

Besides the mentioned external factors, there were several personal attributes identified as the moderators altering people's sense of community namely age, gender, parenting, stage of life, socioeconomic status, cultures, etc. (Chipuer \& Pretty, 1999; Dupuis \& Thorns, 1998; Gifford, 2007). At a more profound level, personality, social behaviors, and psychological status of the residents themselves also defined as the determinants affecting their sense of community. Additionally, a deficient social interaction of person was assumed to associate with more demand for privacy and isolation, and the extent of individualism. On the other hand, the devotion on social capital and participation was considered galvanizing the pro-social behavior as well as strengthening the bonding between members and community. (Long \& Perkins, 2007; Putnam, 2000)

\subsection{Research Questions and Hypotheses}

As per research objectives and the above-mentioned circumstances, the central questions of this multidisciplinary study were defined as follows: (a) Which environmental-psychological determinants do significantly influence the sense of community of high-rise dwellers in the urban context of Bangkok Metropolis? (b) How do these determinants causatively affect the sense of community? The theoretical framework and hypothesized effects between dependent and independent variables are illustrated in the below diagram.

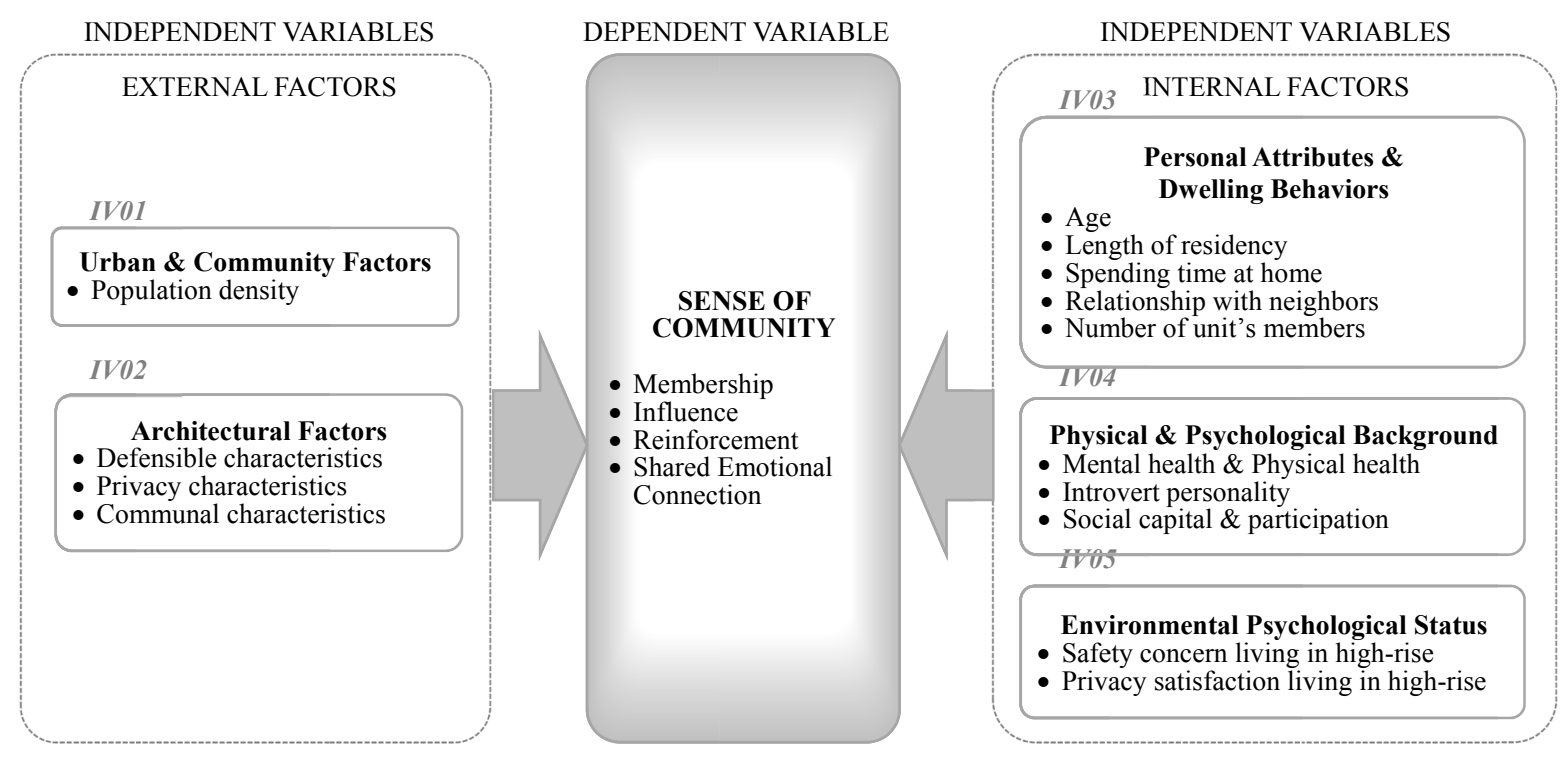

Figure 1. Research theoretical framework

The above diagram depicts the research hypotheses assuming the existence of causality between independent variables and the dependent variable, the sense of community. Regarding the variable construct, the independent variables were primarily categorized into two broad groups as follows:

1) External factors refer to the determinants involving the physical environmental context of the high-rise dwellers encompassing two subcategories containing their own indicators:

IV01: Urban and community factors comprise one indicator, population density.

IV02: Architectural factors focus on architectural features of the condominiums composed of three indicators, namely, defensible characteristic, privacy-supportive characteristic, and communal characteristic of the building. 
2) Internal factors refer to the determinants related to the dwellers themselves. Three subcategories belong to this group are as follows:

IV03: Personal attributes and dwelling behavioral factors involve the following individuals' character and living behaviors: age, a length of residency, spending time at home, relationship with neighbors, and the number of unit's members.

IV04: Physical and psychological background factors consist of four indicators which are a physical health condition, mental health condition, demand for privacy (introvert personality), and social capital and participation.

IV05: Environmental psychological factors refer to the two fundamental feelings of the residents to their high-rises, namely, the safety concern and privacy satisfaction of living in high-rise housing.

In the meantime, the dependent variable, sense of community, comprises four main psychological categories: the feelings of (a) membership, (b) reciprocal influence, (c) community reinforcement, and (d) shared emotional connection.

\section{Research Methodology}

\subsection{Research procedures}

On the basis of quantitative approach, this cross-sectional field survey was designed and divided into three major steps as follows:

\section{Step 1: Content validity evaluating}

After hypothesis setting and research tools constructing, the main research instrument, Personal and Environmental Psychological (PEP) questionnaire, was assessed by employing an Item Objective Congruence (I.O.C) solution. The preliminary questionnaire was evaluated and scored $(-1,0$, and +1$)$ by a group of five experts encompassing housing researchers and professionals. The results of I.O.C. indicated that none of question items earned an average rating lower than minimum standard (0.6). Nevertheless, some question items were readjusted based on the comments derived from the experts.

Step 2: Reliability of a psychometric test estimating

To determine the reliability of the psychological questionnaire, the pilot study was performed along with the revised PEP questionnaire and the Physical Environmental (PE) assessment at one of the randomly selected residential high-rise located in Southern Bangkok area conducive to calculating the internal consistency of the questionnaire. The outcome revealed the Cronbach's Alpha coefficient $(\alpha)=0.847$, which was considered as a good internal consistency.

Step 3: Full-scale field survey

At this stage, the final PEP questionnaires were distributed to the residents of all sampled condominiums. The respondents were requested to willingly complete all set forth questions involved the personal information based on the variable construct delineated in section 1.4. In the meantime, the PE assessments were administered to evaluate the physical environmental conditions of each condominium.

\subsection{Sampling technique}

Due to a large number of condominiums located in the vast urban area of Bangkok, the multi-stage sampling technique consisted of the following stages was implemented to recruit the participants of this study:

Stage 1: Cluster sampling technique

At this juncture, the high-rise housing population was twofold segmented. Firstly, it was divided by a geographical cluster of which composed six different zones according to Bangkok Metropolitan Administration (BMA): (a) Zone 1: Northern Bangkok, (b) Zone 2: Central Bangkok, (c) Zone 3: Southern Bangkok, (d) Zone 4: Eastern Bangkok, (e) Zone 5: Northwestern Bangkok (Northern Thonburee), and (f) Zone 6: Southwestern Bangkok (Southern Thonburee). (Strategy and Evaluation Department, 2014) Afterwards, the condominiums located in each zone of the city were categorized by an economic sub-cluster comprised three levels of condominiums: (a) low-selling price (less than 50,000 Baht $(€ 1,250)$ per $\left.\mathrm{m}^{2}\right)$, (b) middle-selling price $(50,000$ 79,999 Baht $(€ 1,250-1,999)$ per $\mathrm{m}^{2}$, (c) high-selling price (equal or greater than 80,000 Baht $(€ 2,000)$ per $\left.\mathrm{m}^{2}\right)$. (REIC, 2010)

Stage 2: Purposive sampling technique

The purpose of this step was to specify the desirable qualifications of the residential high-rise. The following 
selection criteria were set forth before sending the requested notification of authorization to each condominium.

1) The participating condominium must be a residential high-rise, which is higher than 23 meters.

2) The participating condominium must be operated and occupied more than five years.

At the end of this stage, there were eighteen condominiums, which were located in six different zones of Bangkok and represented three economic sub-clusters, agreed to participate this study and allowed the researcher to further the physical environmental observation and distribute the survey to their residents.

Stage 3: Random sampling technique

A random sample selection was implemented at the final stage. The inhabitants who were living in eighteen participating condominiums were recruited to complete the PEP questionnaire on their willingness.

\subsection{Sample size}

The sampling size of this study was set forth based on Taro Yamane's sample size calculation. Due to the fact that the presumptive number of high-rise dwellers population in Bangkok was more than 200,000(Population Statistics Group, 2010), the desired number of the respondents of this study, therefore, was between 1,111 and 1,222 at \pm 3 percent level of precision, and 10 percent response rate. (Israel, 1992; Yamane, 1967) At the end of the survey, the total number of participating high-rise dwellers was 1,206 .

\subsection{Study Area}

As mentioned earlier in section 2.2, this study geographically clustered Bangkok metropolitan area into six zones and economically categorized the residential high-rises into three levels. Subsequently, there were eighteen qualified condominiums agreed to engage the survey and allowed the researcher to further the physical environmental observation and distribute the questionnaires to their residents. The below map of Bangkok Metropolis illustrates the geographical clustering as well as the locations of all participating condominiums as the research settings. (See Figure 2.)

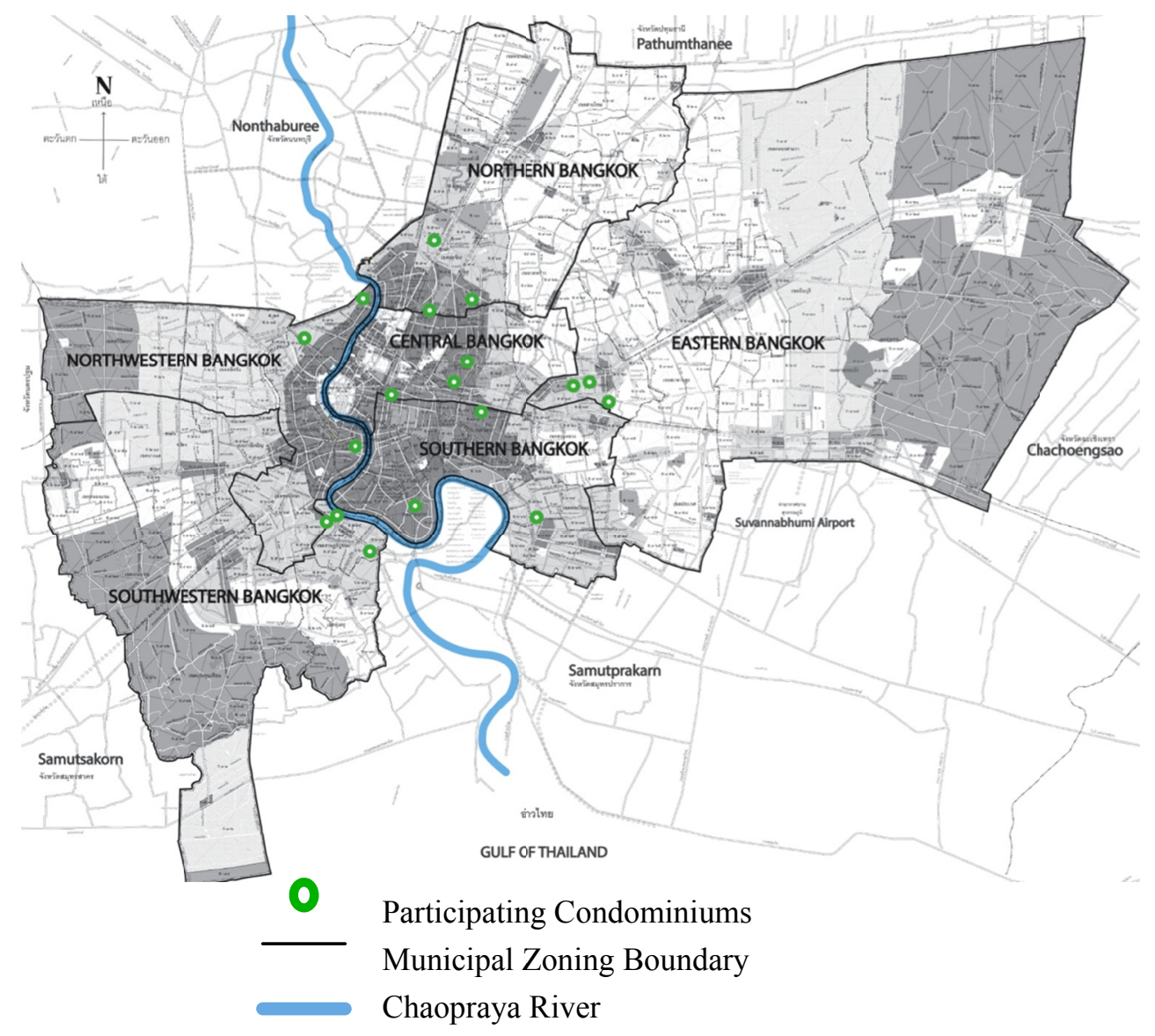

Figure 2. Map of Bangkok metropolitan area and the locations of participating condominiums 


\subsection{Measures}

The PEP questionnaire employed self-report measurement to gain information from participants. Concerning the psychological variables, the psychometric rating scale (one to five) was implemented to measure the degree of the respondents' sense of community as well as their safety concern and privacy satisfaction.

\section{Results}

\subsection{Demographic Analysis}

Regarding the results of the field survey, the total number of the participants was 1,206. Among them, there were $683(56.6 \%)$ females and $523(43.4 \%)$ males. The average age of respondents was 32.8 years old, whereas, the mode and median of household income were 50,000 baht (approximately $€ 1,280$ ) per month. Considering the geographical cluster, there were $215,200,195,178,207$, and 211 respondents $(17.8 \%, 16.6 \%, 16.2 \%, 14.8 \%$, $17.2 \%$, and 17.5\%), who were living in Zone1 to Zone6 consecutively. Meanwhile, there were 404, 425, and 377 respondents $(33.5 \%, 35.2 \%$, and $31.3 \%)$ living in the low, middle, and high selling price condominiums consecutively.

\subsection{Physical environmental (PE) assessment}

As defined in section 1.4, there were three independent variables applied for assessing the physical environment of the condominiums. The numerical data of each variable obtained from scoring its sub-indicators measured via the process of nonparticipant observation along with the PE assessment. These architectural variables including their indicators, sub-indicators, and scoring system are delineated in the below table. (See Table 1.)

Table 1. Summary of the physical environmental variables, indicators, sub-indicators, and scoring system

\begin{tabular}{|c|c|c|c|}
\hline Independent Variables & Indicators & Sub-indicators & Scoring \\
\hline \multirow{4}{*}{$\begin{array}{l}\text { Defensible Characteristic of } \\
\text { Condominium }\end{array}$} & Access Control & $\begin{array}{l}\text { Number of gate(s), Frequency of security check point(s), } \\
\text { Number of vehicle barrier(s) }\end{array}$ & 1 to 5 \\
\hline & Surveillance & $\begin{array}{l}\text { Number of security guard(s) per bldg. and CCTV installed } \\
\text { position }\end{array}$ & 1 to 5 \\
\hline & Territoriality & Level of barricade, Allowance for non-residents' access & 1 to 5 \\
\hline & Milieu \& Juxtaposition & $\begin{array}{l}\text { Walking distance to public transport, Chaotic surrounding } \\
\text { and heterogeneity, Building maintenance quality }\end{array}$ & 1 to 5 \\
\hline \multirow{2}{*}{$\begin{array}{c}\text { Privacy-Supportive } \\
\text { Characteristic of } \\
\text { Condominium }\end{array}$} & Floor Density & Number of units per floor & 1 to 5 \\
\hline & Typical Floor Plan & $\begin{array}{c}\text { Double-loaded corridor, Single-loaded corridor, } \\
\text { Non-corridor, Atrium }\end{array}$ & 1 to 5 \\
\hline \multirow{2}{*}{$\begin{array}{l}\text { Communal Characteristic of } \\
\text { Condominium }\end{array}$} & Variety of shared facilities & Number of shared facilities & 1 to 5 \\
\hline & Accessibility to shared facilities & Socio-fugal, Socio-petal, and Exclusive & 1 to 5 \\
\hline
\end{tabular}

The operationalized indicators and scoring system demonstrated in the above table were implemented with all participating condominiums during the field survey. The samples of existing conditions of condominiums are illustrated in Figure 3, whereas, the outcomes derived from the field survey are indicated in Table 2.
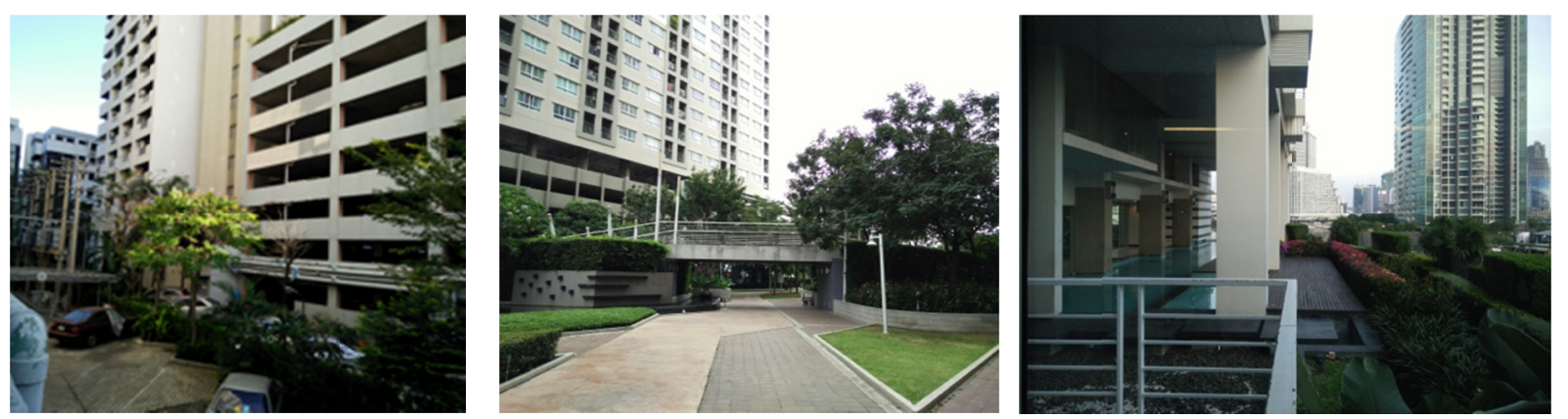

Figure 3. Environmental conditions of low-selling price condominium (left), middle-selling price condominium (middle), and high-selling price condominiums (right) 
Table 2. Summary of Physical Environmental score of eighteen condominiums

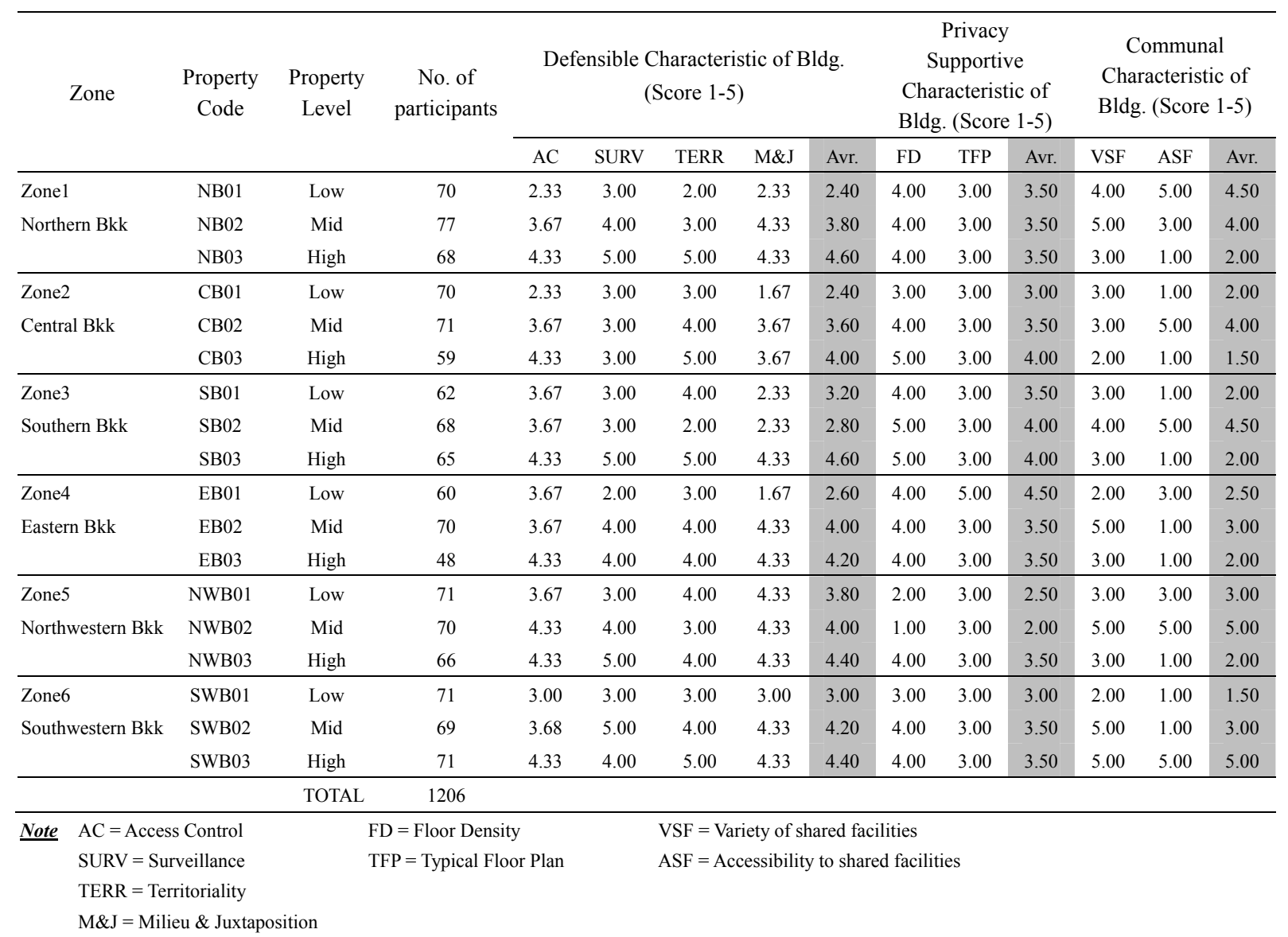

Regarding the PE assessment, it appeared that the high selling price condominiums earned the highest average score of the defensible characteristic among others, whereas, the low selling price condominiums received the lowest defensible characteristic scores. The results also demonstrated that the average score of the privacy-supportive characteristic of all three levels: low, middle, and high selling price condos were not dramatically different. However, it was notable that the condominiums in the group of high selling price averagely owned the better score of privacy features than others. Considering the communal characters of the condominiums, it revealed that averagely the condominiums in the group of middle selling price properties received the better score of the communal characteristic than other levels.

\subsection{Personal and environmental-psychological (PEP) analysis}

As the primary dependent variable, sense of community of the respondents was measured by the psychometric scaled questions (rating-scale type: one to five) contained in the PEP questionnaire. The table below demonstrates an operationalization and scoring system of this dependent variable. (See Table 3.)

Table 3. Summary of indicators, question items, and scoring system of the sense of community

\begin{tabular}{|c|c|c|c|c|c|c|c|}
\hline \multirow{3}{*}{$\begin{array}{l}\text { Dependent Variable } \\
\text { Sense of Community }\end{array}$} & \multirow{3}{*}{$\begin{array}{c}\text { Indicators } \\
\text { Feeling of Membership }\end{array}$} & \multirow{3}{*}{$\begin{array}{c}\text { Question Items } \\
\text { You feel that.... } \\
\text { You are a member of community/ being treated well }\end{array}$} & \multicolumn{5}{|c|}{ Level of feeling } \\
\hline & & & \multicolumn{5}{|c|}{ Slightly $>>>>$ Strongly } \\
\hline & & & 1 & 2 & 3 & 4 & 5 \\
\hline & & Your neighbors can recognize you and vice versa & 1 & 2 & 3 & 4 & 5 \\
\hline & Feeling of Influence & Your request or complaint are always listened & 1 & 2 & 3 & 4 & 5 \\
\hline & & Your neighbors'opinions or suggestion are useful & 1 & 2 & 3 & 4 & 5 \\
\hline & Feeling of Reinforcement & You are happy to participate the community's events & 1 & 2 & 3 & 4 & 5 \\
\hline & & Your neighbors are kind and helpful & 1 & 2 & 3 & 4 & 5 \\
\hline & Shared Emotional Connection & You will be angry if someone criticize or defame this building & 1 & 2 & 3 & 4 & 5 \\
\hline & & $\begin{array}{l}\text { You feel bound with this place and hope to live here as long as } \\
\text { you can }\end{array}$ & 1 & 2 & 3 & 4 & 5 \\
\hline
\end{tabular}


The results of PEP questionnaire indicated that averagely the sense of community score of this sampling group was 3.32/5. In more detail, the average scores of the feeling of membership, influence, reinforcement, and shared emotional connection, were $3.43,3.21,3.23$, and 3.41 respectively. The bar graph below demonstrates the average scores of four sub-variables of the sense of community comparatively by six zones of Bangkok. (See Figure 4.)

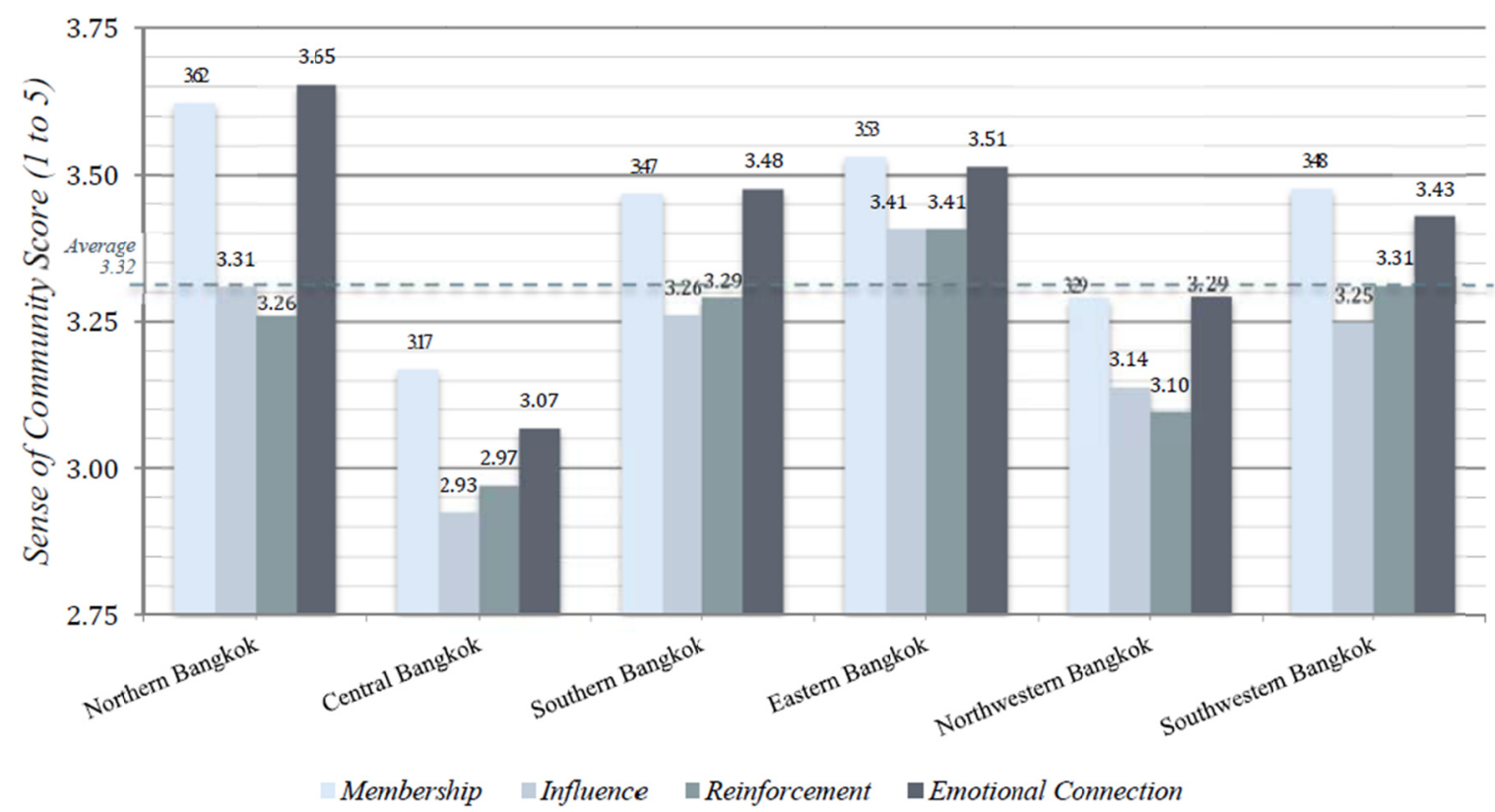

Figure 4. Comparing of four elements of the sense of community: membership, influence, reinforcement, and emotional connection, by zoning of Bangkok

The above diagram shows that among the six zones of Bangkok metropolitan area, high-rise residents of Zone 2 (Central Bangkok) apparently reported the least average scores of the sense of community and all four encompassed elements.

By employing a one-way analysis of variance (one-way ANOVA), the significant effects of Bangkok municipal zoning on the dwellers' sense of community were confirmed at $F(5,1200)=11.295, p$-value $=.000$. Considering each sub variable, it was found that the city zoning affected the feeling of membership at $F(5,1200)=8.326$, $p$-value $=.000$, reciprocal influence at $F(5,1200)=7.216, p$-value $=.000$, communal reinforcement at $F(5,1200)$ $=7.848, p$-value $=.000$, and shared emotional connection at $F(5,1200)=10.857, p$-value $=.000$. The Post Hoc comparisons indicated that the high-rise residents from Zone 2: Central Bangkok significantly had the weakest sense of community, feeling of membership, influence, reinforcement, and emotional connection among the other zones, except Zone 5: Northwestern Bangkok. (See Table 4.)

Table 4. Summary of one-way ANOVA results: sense of community, membership, influence, reinforcement, and emotional connection scores compared by six zones of Bangkok

\begin{tabular}{|c|c|c|c|c|c|c|c|c|c|c|c|c|c|c|c|}
\hline \multirow[b]{2}{*}{ Dependent Variables } & \multicolumn{2}{|c|}{$\begin{array}{l}\text { Zone1: } \\
\text { Northern }\end{array}$} & \multicolumn{2}{|c|}{$\begin{array}{l}\text { Zone2: } \\
\text { Central }\end{array}$} & \multicolumn{2}{|c|}{$\begin{array}{l}\text { Zone3: } \\
\text { Southern }\end{array}$} & \multicolumn{2}{|c|}{$\begin{array}{l}\text { Zone4: } \\
\text { Eastern }\end{array}$} & \multicolumn{2}{|c|}{$\begin{array}{c}\text { Zone5: } \\
\text { N.Western }\end{array}$} & \multicolumn{2}{|c|}{$\begin{array}{c}\text { Zone6: } \\
\text { S.Western }\end{array}$} & \multicolumn{2}{|l|}{$F$} & \multirow{2}{*}{$\begin{array}{c}\text { Post Hoc Test } \\
\text { Scheffe }\end{array}$} \\
\hline & Mean & S.D. & Mean & S.D. & Mean & S.D. & Mean & S.D. & Mean & S.D. & Mean & S.D. & $(5,1200)$ & p-value & \\
\hline Sense of Community & 3.462 & 0.742 & 3.033 & 0.757 & 3.375 & 0.660 & 3.487 & 0.684 & 3.205 & 0.753 & 3.367 & 0.728 & 11.295 & $.00^{* * *}$ & $2<1,3,4,6 / 5<1,4$ \\
\hline Membership & 3.623 & 0.841 & 3.170 & 0.853 & 3.469 & 0.794 & 3.531 & 0.785 & 3.291 & 0.859 & 3.478 & 0.791 & 8.326 & $.00^{* * *}$ & $2<1,3,4,6 / 5<1$ \\
\hline Influence & 3.309 & 0.869 & 2.925 & 0.894 & 3.262 & 0.850 & 3.407 & 0.807 & 3.139 & 0.864 & 3.249 & 0.911 & 7.216 & $.00^{* * *}$ & $2<1,3,4,6$ \\
\hline Reinforcement & 3.260 & 0.926 & 2.970 & 0.895 & 3.292 & 0.864 & 3.494 & 0.864 & 3.096 & 0.906 & 3.310 & 0.940 & 7.848 & $.00^{* * *}$ & $2<3,4,6 / 5<4$ \\
\hline Emotional Connection & 3.654 & 0.888 & 3.068 & 0.953 & 3.477 & 0.811 & 3.514 & 0.834 & 3.293 & 0.891 & 3.430 & 0.878 & 10.857 & $.016^{*}$ & $2<1,3,4,6 / 5<1$ \\
\hline
\end{tabular}

${ }^{* * *}$-value $<.001, * * p$-value $<.005, * p$-value $<.05$

The sense of community scores compared by three levels of condominium, are illustrated in the bar graph below. (See Figure 5.) 


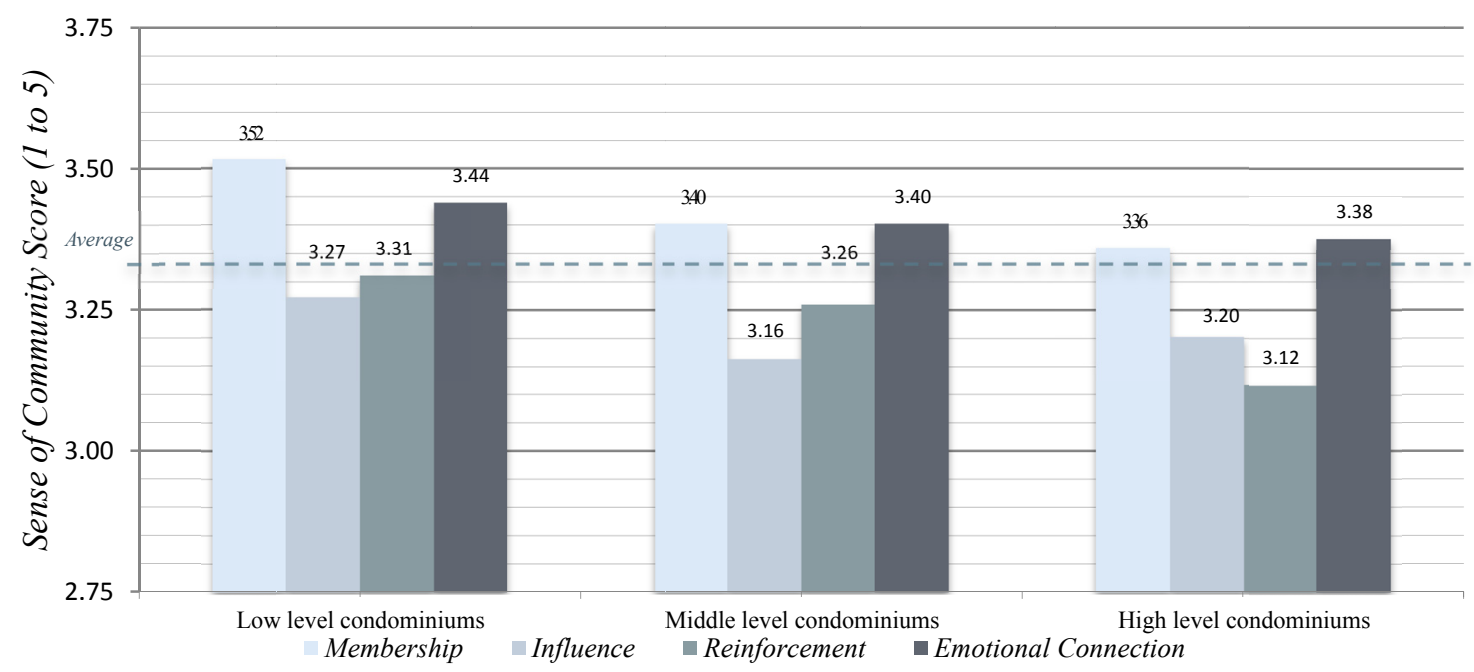

Figure 5. Comparing of four elements of the sense of community: membership, influence, reinforcement, and emotional connection, by level of condominium

According to the information shown in the above diagram, it appeared that there were slight differences in the degree of the sense of community among the residents from all levels of the property. Nevertheless, the descriptive statistics indicated that the residents of low selling price condominiums revealed the highest average score of the sense of community (3.38/5) followed by the groups of middle and high selling price condominiums (3.31/5 and 3.26/5) consecutively.

The one-way ANOVA statistically confirmed that the degree of the feeling of membership and reinforcement reported by the dwellers of high selling price condominiums were significantly less than those who lived in the low selling price condominiums at $F(2,1203)=3.742$, p-value $=.024$ and $F(2,1203)=4.755$, $p$-value $=.009$ respectively. (See Table 5.)

Table 5. Summary of one-way ANOVA results: sense of community, membership, influence, reinforcement, and emotional connection scores by three levels of condominium

\begin{tabular}{|c|c|c|c|c|c|c|c|c|c|}
\hline \multirow[b]{2}{*}{ Dependent Variables } & \multicolumn{2}{|c|}{$\begin{array}{c}\text { Level } 1 \\
\text { Low selling price }\end{array}$} & \multicolumn{2}{|c|}{$\begin{array}{c}\text { Level } 2 \\
\text { Middle selling price }\end{array}$} & \multicolumn{2}{|c|}{$\begin{array}{c}\text { Level } 3 \\
\text { High selling price }\end{array}$} & \multirow{2}{*}{$\begin{array}{c}F \\
(2,1203)\end{array}$} & \multirow[b]{2}{*}{ p-value } & \multirow{2}{*}{$\begin{array}{c}\text { Post Hoc Test } \\
\text { Scheffe }\end{array}$} \\
\hline & Mean & S.D. & Mean & S.D. & Mean & S.D. & & & \\
\hline Membership & 3.516 & 0.818 & 3.402 & 0.849 & 3.359 & 0.829 & 3.742 & $.024 *$ & $3<1$ \\
\hline Reinforcement & 3.312 & 0.88 & 3.26 & 0.949 & 3.117 & 0.899 & 4.755 & $.009^{*}$ & $3<1$ \\
\hline
\end{tabular}

$* * * p$-value $<.001, * * p$-value $<.005, * p$-value $<.05$

\subsection{Causal analysis}

During the causal analytical stage, the multiple linear regression analysis (MLR) was performed to determine the hypothetical effects of multiple independent variables on the sense of community of high-rise residents as well as to conclude the predictive model for this particular psychological variable. According to the theoretical assumption, the following sixteen numerical variables were put into the MLR computation as the predictors of the sense of community. (See Table 6.)

Table 6. Summary of the predictors encompassed in the MLR causal modeling

\begin{tabular}{|c|c|c|}
\hline & Category & Independent Variables/ Predictors (Abbreviation) \\
\hline IV01 & Urban and community factors: & Population density (POP) \\
\hline IV02 & Architectural factors: & $\begin{array}{l}\text { Height of building (HEI), Defensible characteristic score (DEFB), Privacy supportive characteristic } \\
\text { score (PRVB), Communal-characteristic score (COMB) }\end{array}$ \\
\hline IV03 & $\begin{array}{l}\text { Personal attributes and dwelling } \\
\text { behavioral factors: }\end{array}$ & $\begin{array}{l}\text { Age (AGE), Length of residency (LR), Spending time at home (TIME), Relationship with neighbors } \\
\text { (RE), Number of unit's members (UDEN). }\end{array}$ \\
\hline IV04 & Physical and psychological factors: & $\begin{array}{l}\text { Health condition score (HLTH), Mental health condition score (MHLTH), Demand for privacy/ } \\
\text { Introversion (INTRV), Social capital and participation (SOCAP). }\end{array}$ \\
\hline IV05 & Environmental psychological factors: & Safety concern (SAF), Privacy satisfaction (PRVS) \\
\hline
\end{tabular}


The stepwise method was pursued to achieve the regression model-fitting process acquiescing the final model at the significance level of 0.05 ( $95 \%$ confidence interval).

The results of the MLR analysis indicated that the set of ten predictors from five categories (IV01-IV05) was confirmed being able to explain $29.4 \%$ of the variance of the sense of community reported by this sampling group. Aftermath, the tenth model confirmed the predictive equation at $R^{2}=.294, F(10,1191)=49.505$, $p$-value $=.000$. The summary of model-fitting process and estimates are elucidated in Table 7 .

Table 7. Summary of the model-fitting process for the sense of community

\begin{tabular}{|c|c|c|c|c|c|c|}
\hline Predictors & $R$ & $R^{2}$ & $R_{\text {change }}^{2}$ & S.E.est & $F$ & $p$-value \\
\hline${ }^{1} \mathrm{SOCAP}$ & .307 & .094 & .094 & .702 & 124.791 & $.000^{* * *}$ \\
\hline${ }^{2}$ SOCAP, PRVS & .414 & .172 & .077 & .672 & 124.120 & $.000^{* * *}$ \\
\hline${ }^{3}$ SOCAP, PRVS, RE & .464 & .215 & .044 & .654 & 109.626 & $.000^{* * *}$ \\
\hline${ }^{4}$ SOCAP, PRVS, RE, POP & .492 & .242 & .026 & .643 & 95.417 & $.000^{* * *}$ \\
\hline${ }^{5}$ SOCAP, PRVS, RE, POP, INTRV & .515 & .266 & .024 & .633 & 86.520 & $.000^{* * *}$ \\
\hline${ }^{6}$ SOCAP, PRVS, RE, POP, INTRV, MHLTH & .530 & .280 & .015 & .627 & 77.597 & $.000^{* * *}$ \\
\hline${ }^{7}$ SOCAP, PRVS, RE, POP, INTRV, MHLTH, COMB & .534 & .285 & .005 & .625 & 68.117 & $.000^{* * *}$ \\
\hline${ }^{8}$ SOCAP, PRVS, RE, POP, INTRV, MHLTH, COMB, DEFB & .537 & .289 & .003 & .624 & 60.499 & $.000^{* * *}$ \\
\hline${ }^{9}$ SOCAP, PRVS, RE, POP, INTRV, MHLTH, COMB, DEFB, SAF & .540 & .291 & .003 & .623 & 54.443 & $.000^{* * *}$ \\
\hline${ }^{10}$ SOCAP, PRVS, RE, POP, INTRV, MHLTH, COMB, DEFB, SAF, PRVB & .542 & .294 & .002 & .623 & 49.505 & $.000^{* * * *}$ \\
\hline
\end{tabular}

${ }^{* * *} p$-value $<.001, * * p$-value $<.005, * p$-value $<.05$

According to the final stepwise regression model indicated in Table 7., the statistics and estimates of all ten significant predictors are continually described in the below table. (See Table 8.)

Table 8 . Predictive regression model for the sense of community

\begin{tabular}{|c|c|c|c|c|c|c|c|c|c|}
\hline & & \multirow{3}{*}{ Predictors } & \multicolumn{7}{|c|}{ Predictive Model for Sense of Community } \\
\hline & & & \multicolumn{2}{|c|}{ Collinearity Statistics } & \multicolumn{5}{|c|}{ (Stepwise Method: Model 10 ${ }^{\text {th }}$ ) } \\
\hline & & & Tol. & $V I F$ & $b$ & S.E. & $\beta$ & $t$ & p-value \\
\hline IV01 & POP & Density of Population & .932 & 1.073 & $-3.30 \mathrm{E}-05$ & .000 & -.155 & -6.137 & $.000^{* * *}$ \\
\hline \multirow[t]{3}{*}{ IV02 } & DEFB & Defensible Score of Bldg. & .931 & 1.074 & -.063 & .026 & -.062 & -2.474 & $.013^{*}$ \\
\hline & PRVB & Privacy Supportive Score of Bldg. & .949 & 1.054 & -.062 & .031 & -.049 & -1.970 & $.049^{*}$ \\
\hline & COMB & Communal Score of Bldg. & .970 & 1.031 & .039 & .015 & .063 & 2.558 & $.011^{*}$ \\
\hline IV03 & $\mathrm{RE}$ & Relationship with Neighbors & .853 & 1.172 & .090 & .015 & .159 & 6.038 & $.000^{* * *}$ \\
\hline \multirow[t]{3}{*}{ IV04 } & INTRV & Introversion & .901 & 1.110 & -.033 & .007 & -.127 & -4.947 & $.000^{* * *}$ \\
\hline & SOCAP & Social Capital/ Participation & .873 & 1.146 & .023 & .003 & .200 & 7.679 & $.000^{* * *}$ \\
\hline & MHLTH & Mental Health Score & .931 & 1.075 & .086 & .017 & .125 & 4.949 & $.000^{* * *}$ \\
\hline \multirow[t]{2}{*}{ IV05 } & SAF & Average Safety Concern & .963 & 1.039 & -.043 & .019 & -.056 & -2.272 & $.023^{*}$ \\
\hline & PRVS & Average Privacy Satisfaction & .971 & 1.030 & .253 & .024 & .266 & 10.744 & $.000^{* * *}$ \\
\hline
\end{tabular}

Constant $=2.390$, S.E.est $=.623$

$$
R=.542, R^{2}=.294, F(10,1191)=49.50, p \text {-value }=.000^{* * *}
$$

$* * *$-value $<.001, * *$ p-value $<.005, *$ p-value $<.05$

Note: (a) All predictive regression models were under the conditions that all variables were measured with the defined units of PE assessment and PEP questionnaire. (b) The collinearity diagnostic confirmed no multicollinearity between regressors. (There was no independent variable that owned Variance Inflation Factor (VIF) greater than 4 and the Tolerance (Tol.) lower than 0.2)

As defined in Table 8., the predictive regression modeling extracted ten significant regressors from all factor categories hypothesized at the beginning. The statistics described in the table could be interpreted that the predicted sense of community score of the respondents significantly increased by $0.039,0.023,0.086,0.090$, and 0.253 for each increasing point of communal score of the building (COMB), social capital and participation score (SOCAP), mental condition score (MHLTH), relationship with neighbors score (RE), and the average score of privacy satisfaction (PRVS) consecutively. On the other hand, the sense of community significantly decreased $-3.30 \mathrm{E}-05,0.063,0.062,0.033$ and 0.043 for each person of the population density per $\mathrm{km}^{2}$ (POP), increasing point of the defensible score of the building (DEFB), privacy-supportive score of the building (PRVB), introversion score (INTRV), and the average of safety concern (SAF) respectively. The predictive equation for the sense of community of high-rise dwellers confirmed by the MLR computation is described below. 
Sense of Community predicted $=2.390+(.023 * S O C A P)+(.253 * P R V S)+(.09 * R E)-(3.30 E-05 * P O P)-(.033 * I N T R V)$

$$
+(.086 * M H L T H)+(.039 * C O M B)-(.063 * D E F B)-(.043 * S A F)-
$$

Nevertheless, it is noteworthy that there were six variables excluded from the final model, namely, Height of building (HEI), Privacy supportive characteristic score (PRVB), Age (AGE), Length of residency (LR), Number of unit's members (UDEN), Spending time at home (TIME), and Health condition score (HLTH).

\section{Discussion}

\subsection{Influences of urban context on the sense of community}

As mentioned in section 3.2, the descriptive statistical results indicated that the sense of community of high-rise residents participating this survey diverged by the particular context of each urban zone of Bangkok. When comparing the average score of the sense of community and its sub-variables reported by residents of each area, the Post Hoc results endorsed that the respondents residing in Zone 2: Central Bangkok significantly retained the weakest sense of community including the feeling of membership, influence, reinforcement, and emotional connection.

Contemplating the urban context and land use policy of Central Bangkok, it is well known that this area is the central business district (CBD) of the city, and of the country. Despite being a hub of amenities, infrastructure, and convenience, people who live in the area of Central Bangkok have to confront several daily life's dilemmas, for instance, a high cost of living, severe traffic congestion, air and noise pollution, etc. A comparative analysis of the dataset defined that Central Bangkok significantly had a double time of population density $(13,677$ persons $\left./ \mathrm{km}^{2}\right)$ than the average of other zones of Bangkok $\left(6,244\right.$ persons $\left./ \mathrm{km}^{2}\right)$ at $p$-value $=.000$. As well, the dataset analysis confirmed that the high-rise dwellers living in Central Bangkok reported the least frequency of social participation, youngest average age (30 year-old), and shortest length of residency (40.36 months) among other zones significantly at $p$-value $=.000$.

These statistical confirmations integrated the demographic data pointed out that a competitive lifestyle, densification, and restless environment could be the cofactors causing them exhaustive conditions and lack of vitality to get involved with their neighbors as well as the temporary intention of residency was implying their unbounded sensation to the community.

Additionally, by employing the Cohen's magnitude of effect $(f)$ and statistical power calculation, it is noteworthy to report that there was approximately $100 \%$ chance of detecting this small to medium-sized effect of city zoning on the sense of community among this sampling group. $(f=.22$ and Power $(1-\beta)=1.00$ at $N=1206, \alpha$ error probability $=0.05$, Power $(1-\beta)$ error probability $=0.8)$

\subsection{Influences of level of property on the sense of community}

As reported in section 3.3, the economic level of condominiums significantly affected the dwellers' sense of community at the $95 \%$ confidence interval. The results of one-way ANOVA calculation confirmed its effects particularly on the respondents' feeling of membership and reinforcement at $p$-value $=.024$ and .009 respectively The Post Hoc comparisons indicated that the respondents from the low-level condominiums had the stronger feeling of membership and reinforcement with their community than those who were living in high-level condominiums significantly.

Regarding the PE assessment, the communal-characteristic score of the low-level condominiums (2.595/5) was slightly higher than the high-level condominiums' (2.486/5). Also, surveying the architectural features of these condominiums exposed that the low selling price condos mostly were the semi-gated compound, which not only provided various facilities for their residents but also allowed non-residents to share and access those premises easily. Besides, the locations of such recreational facilities were more accessible and sociopetal. Conversely, most of the high-level condominiums provided fewer recreational facilities only for their residents plus such areas were located exclusively from public sight as much as possible to achieve the highest level of privacy.

According to their dwelling behavioral data, it indicated that the low-level condominiums' residents had been living in their buildings for a longer period (averagely 60 months) than those from the high-level condos (averagely 37 months) significantly at $p$-value $=.000$. Moreover, the respondents from the low-level condominiums had the higher average score of relationship with neighbors and spending time at home more than the high-level condominium's residents significantly at $p$-value $=.000$. The comparative analysis of the respondents' personality also revealed that the respondents from the high-level properties were likely more introvert than the low-level residents significantly at $p$-value $=.034$.

Besides the architectural conditions differed by level of the property, the above-mentioned statistical comparison 
had signified the impacts of other cofactors that potentially varied the high-rise residents' sense of community, which were further investigated during the causal modeling by the MLR method.

As a single factor, the effect of the level of property on the sense of community per se is still unconfirmed by this study due to the fact that the Cohen's magnitude of effect $(f)$ and statistical power calculation showed that there were less than $80 \%$ chances to identify the small-sized effects of the level of condominium on the feeling of membership $(f=.079$ and Power $(1-\beta)=.69)$, and reinforcement $(f=.089$ and Power $(1-\beta)=.79)$ respectively.

\subsection{Interpretation of predictive regression model for the sense of community}

The causal MLR model defined in the previous section confirmed that the ten predictors could associatively explain approximately $30 \%$ variance of the sense of community among high-rise residents participating in this survey. Notably, the input data of the predictive equation needs to be measured under the conditions of the PEP questionnaire and the PE assessment described earlier. The following sub-sections contributed to discussing these influential factors in more detail.

\subsubsection{Urban and community factors}

At the urban and community scale, the numerical variable endorsed by the predictive model was the population density. The estimates of this predictor $(b=-3.30 \mathrm{E}-05, \beta=-.155)$ apparently indicated that it was inversely related to the respondents' average score of the sense of community at $p$-value $=.000$. Predictably, every increasing person of the district's population per $\mathrm{km}^{2}$, the sense of community score of the high-rise residents decreased -3.30E-05 (0.000033) significantly. In other words, the more population density of the district at where the condominium was located, the weaker sense of community among the residents was predicted.

The results of this field survey were consistent with previous research and studies, which indicated that the disadvantageous urban lifestyle including the size of the city, density, and heterogeneity of population could cause the overloads of people's cognitive functions, which led to a withdrawal behavior and taking less interest in the community.(Milgram, 1970)

\subsubsection{Architectural factors}

The MLR predictive model also indicated three main architectural indicators, which predominated the high-rise residents' sense of community significantly. To begin with, the defensible characteristic score of the condominium was defined as the factor adversely affecting the sense of community $(b=-.063, \beta=-.062)$ at $p$-value $=.013$. Following the MLR equation, the more score of the defensible characteristic earned by condominium, the less sense of community of the residents was predicted. Regarding the PE assessment, the rigorous access control, providing surveillance throughout the compound, walls, security guards, and gated territoriality that separated the occupants from the outside environment could discourage the social interaction between the residents and non-residents and negatively affect the sense of community among the inhabitants.

Secondly, the privacy-supportive characteristic score of the building was another architectural feature confirmed deterring the respondents' sense of community $(b=-.062, \beta=-.049)$ at $p$-value $=.049$. It could be interpreted that the respondents' sense of community decreased relatively for each increasing privacy-supportive score earned by condominium. These characters referred to (a) the fewer number of units per floor, (b) the fewer number of occupants per unit, and (c) the sociofugal typical floor plan, which was the most beneficial component for supporting the privacy of the residents.

The communal-characteristic score of the building was the third and only physical feature of the condominium that positively related to the sense of community of the dwellers $(b=.039, \beta=.063)$ at $p$-value $=.011$. The trend of the model suggested that the higher score of communal character earned by condominium, the stronger sense of community among the residents was predicted. In more detail, providing more various facilities for the residents, sharing recreational facilities with the non-residents, and sociopetal layout design for these areas could encourage the social interaction among occupants, which will help improve their sense of community as a consequence.

\subsubsection{Personal attributes and dwelling behavioral factors}

The most predictive indicator in this category identified by the MLR model was the relationship with neighbors self-reported by the respondents. The regressive equation revealed that this factor positively varied the degree of the sense of community $(b=.090, \beta=.159)$ at $p$-value $=.000$. The interpretation of this result was that the greater score of relationship with neighbors reported by the respondents, their stronger sense of community was predicted. This statistical confirmation was compatible with the theoretical concept and previous psychological research of which the relationship with neighbors was defined as a relevant indicator generating positive 
outcomes for the residents and community.(Manzo \& Perkins, 2006)

\subsubsection{Physical and psychological factors}

There were three dominant indicators in this category identified by the MLR casual model: demand for privacy/ introversion score, social capital and participation score, and mental health condition score.

The results of the MLR modeling endorsed the degree of introvert personality as one of the factors negatively related to the high-rise residents' sense of community $(b=-.033, \beta=-.127)$ at $p$-value $=.000$. The consonance of statistical outcomes substantiated the psychological mechanism of cultivating people's sense of community, which was built on the social interaction. The results of this field survey affirmed that the sense of community of the high-rise residents was weakened when they tended to be more individualized, introvert, and withdrew themselves from participating public activities.

Social capital and participation behavior of the high-rise dwellers was statistically approved as one of the factors that helped strengthen their sense of community encompassing the feeling of membership, influence, reinforcement, and emotional connection $(b=.023, \beta=.200)$ at $p$-value $=.000$. This result was accordant with the theoretical concept and previous research, which affirmed the intertwining between the different types of social investment, for instance, donation, volunteering, etc. and sense of community of people.(Putnam, 2000)

Meanwhile, the physical health condition was excluded from the regression model; the mental health condition was proved out to have an advantageous impact on the sense of community. The interpretation indicated that the greater score of mental health by which the respondents self-reported, the stronger sense of community was forecasted $(b=.086, \beta=.125)$ at $p$-value $=.000$. This positive influence was implying that the mentally healthier assessment after moving-in the condominium was a repercussion of the more emotional security and the more positive attitude towards their home environment encompassing neighbors and community structure. As a consequence, the sense of community of these respondents was greater than those who reported the worse mental health after moving-in.

\subsubsection{Environmental-psychological factors}

Besides the psychological background of the dwellers, their mental status amid residing in the high-rises was presumed as one of the principal factors altering the degree of the sense of community. As mentioned earlier, the psychological fundamental of a home environment focused in this research encompassed the safety concern and the satisfaction of privacy during living in the condominiums.

In consonance with the hypothesis, the final causal model as well affirmed the negative effect of safety concern on the sense of community $(b=-.043, \beta=-.056)$ at $p$-value $=.023$ and the positive effect of privacy satisfaction on the sense of community $(b=.253, \beta=.266)$ at $p$-value $=.000$. The interpretation of this result is that the sense of community score reduced .043 for each increasing safety concern score, whereas, the sense of community score rose up .253 for each increasing privacy satisfaction score.

Regarding the PEP questionnaire, the respondents who reported the greater concern about the presumptive incidence of crime, behavioral disorders, and emergency in the residential buildings tended to have the less sense of community than those who were feeling more secure. On the other hand, the respondents who expressed more satisfaction of psychological, physical, informational, and social interactional privacy while living in the residential high-rises also had the stronger sense of community than those who feel more unsatisfied.

After performing the Cohen's magnitude and power of effect size $\left(f^{2}\right)$, the MLR model for predicting the sense of community, which comprised the above-mentioned ten predictors, achieved an extra large effect size of $f^{2}=$ 0.416 which was greater than 0.35 as defined by the Cohen's criteria, and earned the maximum power of $100 \%$ chance of detecting (Power $(1-B)=1.00)$. It was explicit that the MLR causal models extracted from this field survey were highly affirmative for the further implementation.

\section{Conclusions and recommendations}

Conclusively, the findings of the causal analysis and the predictive modeling revealed in this research have substantiated the hypothesis predicated on the theoretical concept that the associative effects between various factors both external and internal on the sense of community of high-rise housing residents in Bangkok metropolitan area exist.

Remarkably, the weakest sense of community among this sampling group was reported by the high-rise dwellers living in the central Bangkok area well known as the central business district of the country. As discussed earlier, this phenomenon integrated the demographic data pointed out that the urban lifestyle including the densification and competitive environment entails the social withdrawal and deters the sense of community of high-rise 
residents as a consequence. In connection with the urban context, the regression model statistically confirmed the population density as the numerical urban factor that negatively impacted on the degree of the sense of community. It was also conspicuous that the sense of community was more flourishing among the residents of the low-level condominiums than others. Thus, instead of judging the quality of condominium by its economic level alone, this research recommends to focus intensely on the physical features and managerial approach of the residential high-rise, which potentially improve the sense of community and psychological wellbeing of the residents.

In terms of architecture, the designs for defensibility and privacy, which are the typical characters of the residential high-rises, were statistically indicated as the physical environmental factors that suppressed the sense of community of the inhabitants. In contrast, to enhance the sense of community of the residents, this research recommends that the communal characters of the building, for instance, the variety of recreational and shared facilities, and the sociopetal spatial planning are the architectural components reinforcing the sense of community.

Besides the aforementioned external predictors, personal dwelling behaviors and psychological background of the high-rise residents also exposed their powerful impacts on the sense of community. The quality of relationship with neighbors, the frequency of social participation, and the healthy self-assessed mental condition, were statistically confirmed to have favorable effects on the sense of community of high-rise occupants. On the contrary, the personal demand for privacy that reflected the individualism and introversion of the respondents was proven to have an adverse consequence on this particular mental status.

As per the outcomes suggested by the causal modeling, to promote the sense of community among the high-rise residents, it was also necessary to strengthen their psychological safety and privacy satisfaction throughout the period of residence. These two environmental-psychological foundations were statistically verified to enhance the residents feeling of engagement with their community prominently.

Finally, since the physical-environmental (PE) assessment and the personal and environmental-psychological (PEP) questionnaire initiated particularly for this field survey had achieved the statistical reliability and internal consistency, therefore, the further exploitation of these two research instruments is strongly recommended. Moreover, the longitudinal research is also worthwhile to profoundly monitor the mental alteration among the residents of this vertical habitat diversified by the distinctive urban ecological and architectural context.

\section{Acknowledgement}

This research was fully funded by Bangkok University as a part of the Doctoral degree scholarship program and conducted under the joint supervision of King Mongkut's Institute of Technology Ladkrabang and Institute for Housing and Urban Development Studies (IHS), Erasmus University Rotterdam. The utmost gratitude of the researcher as well goes to all housing experts, property managers, and high-rise housing residents, who participated this research, for their invaluable contributions.

\section{References}

Appleyard, D. (1979). The environment as a social symbol: Within a theory of environmental action and perception. J. of American Planning Assoc., 45(2), 143-153. https://doi.org/10.1080/01944367908976952

Atkinson, R., \& Blandy, S. (2005). Introduction: International perspectives on the new enclavism and the rise of gated communities. Housing Studies, 20(2), 177-186. https://doi.org/10.1080/0267303042000331718

Bess, K. D., Fisher, A. T., Sonn, C. C., \& Bishop, B. J. (2002). Psychological sense of community: Theory, research, and application. In A. T. Fisher, C. C. Sonn \& B. J. Bishop (Eds.), Psychological sense of community research, applications, and implications (pp. 3-22). New York: Springer US. https://doi.org/10.1007/978-1-4615-0719-2_1

Bochner, S., Duncan, R., Kennedy, E., \& Orr, F. (1976). Acquaintance links between residents of a high rise building: An application of the "small world" method. The Journal of Social Psychology, 100(2), 277-284. https://doi.org/10.1080/00224545.1976.9711939

Boonkajai, A. (1993). Impact of condominium on bangkok urban environment (M.Arch).

Chavis, D. M., Lee, K. S., \& Acosta, J. D. (2008). The sense of community (SCI) revised: The reliability and validity of the SCI-2. The 2nd International Community Psychology Conference, Lisboa, Portugal.

Chipuer, H. M., \& Pretty, G. M. H. (1999). A review of the sense of community index: Current uses, factor structure, reliability, and further development. Journal of Community Psychology, 27(6), 643-658. https://doi.org/10.1002/(SICI)1520-6629(199911)27:6<643::AID-JCOP2>3.0.CO;2-B 
DeMartino, M. F., \& Stacey, C. L. (1958). Understanding human motivation. Cleveland : H. Allen,.

Dupuis, A., \& Thorns, D. C. (1998). Home, home ownership and the search for ontological security. The Sociological Review, 46(1), 24-47. https://doi.org/10.1111/1467-954X.00088

Forrest, R., La Grange, A., \& Ngai-Ming, Y. (2002). Neighbourhood in a high rise, high density city: Some observations on contemporary Hong Kong. The Sociological Review, 50(2), 215-240. https://doi.org/10.1111/1467-954X.00364

Gifford, R. (2007). The consequences of living in high-rise buildings. Architectural Science Review, 50(1), 2-17.

Gusfield, J. R. (1975). Community: A critical response. Harper \& Row.

Israel, G. D. (1992). Determining sample size (No. PEOD-6).IFAS.

Jephcott, A. P., \& Robinson, H. (1971). Homes in high flats: Some of the human problems involved in multi-storey housing Oliver and Boyd.

Kraithaworn, P., \& Piasue, N. (2013). Sense of community and perception of neighbourhood environment of senior citizens in slum of bangkok. Ramathibodi Medical Journal, 19(1)

Li, C. (2013). Liveability of high-rise housing estates: Case studies in the inner city of tianjin, China. (Unpublished Doctor of Philosophy). Cardiff University,

Long, A. D., \& Perkins, D. D. (2007). Community social and place predictors of sense of community: A multilevel \& longtitudinal analysis. J. of Comm. Psych., 35(5), 563-581. https://doi.org/10.1002/jcop.20165

Low, S. M. (2001). The edge and the center: Gated communities and the discourse of urban fear: American Anthropologist, 103(1), 45-58. https://doi.org/10.1525/aa.2001.103.1.45

Manzo, L. C., \& Perkins, D. D. (2006). Finding common ground: The importance of place attachment to community participation and planning. Journal of Planning Literature, 20(4), 335-350. https://doi.org/10.1177/0885412205286160

Maslow, A. H. (1958). Higher and lower needs. In M. F. DeMartino, \& C. L. Stacey (Eds.), Understanding human motivations (pp. 48-51). Cleveland: Howard Allen Publishers. https://doi.org/10.1037/11305-005

McMillan, D. W., \& Chavis, D. M. (1986). Sense of community: A definition and theory. Journal of Community Psychology, 14(1), 6-23. https://doi.org/10.1002/1520-6629(198601)14:13.0.CO;2-I

Milgram, S. (1970). The experience of living in cities. Science, 167(3924), 1461-1468. https://doi.org/10.1126/science.167.3924.1461

Population Statistics Group. (2010). The 2010 population and housing census. Bangkok: Statistical Forecasting Bureau, National Statistical Office.

Putnam, R. D. (2000). Bowling alone: The collapse and revival of american community. New York: Simon \& Schuster. https://doi.org/10.1145/358916.361990

REIC. (2010). Real estate information center, annual report 2010.

Rujibhong, S., Upala, P., \& Edelenbos, J. (2016). The psychological evaluation of high-rise dwellers in the public and private housing projects: a case study of the northern area of Bangkok metropolis. European Network for Housing Research 2016, Belfast, Northern Ireland, United Kingdom. , 1(1) 100-116.

Sarason, S. B. (1966). Psychology in community settings; clinical, educational, vocational, social aspects. Wiley.

Strategy and Evaluation Department. (2014). Statistical profile of bangkok municipality administration 2014. (No. 1). Phra Nakorn, Bangkok: BMA.

Takooshian, H. (2005). Urban psychology: Its history and current status. Journal of Social Distress and the Homeless, 14, 2-10. https://doi.org/10.1179/105307805807066310

Wright, S. P. (2004). Exploring psychological sense of community in living-learning programs and in the university as a whole (Unpublished Doctor of Philosophy). University of Maryland,

Yamane, T. (1967). Elementary sampling theory. Englewood Cliffs, N.J.: Prentice-Hall.

\section{Copyrights}

Copyright for this article is retained by the author(s), with first publication rights granted to the journal.

This is an open-access article distributed under the terms and conditions of the Creative Commons Attribution license (http://creativecommons.org/licenses/by/4.0/). 